\title{
ON FUNCTIONS WHOSE DERIVATIVE HAS POSITIVE REAL PART
}

\author{
D. K. THOMAS
}

\begin{abstract}
Let $R$ be the class of normalised analytic functions $f$, defined in the open disc $D$, such that $\operatorname{Re} f^{\prime}(z)>0$ for $z \in D$. For $f \in R$, a best possible growth estimate for $\left|z f^{\prime}(z) / f(z)\right|$ is obtained.
\end{abstract}

1. Introduction. Denote by $R$ the class of functions $f$ which are regular in $D=\{z:|z|<1\}$ satisfying $f(0)=0, f^{\prime}(0)=1$, and $\operatorname{Re} f^{\prime}(z)>0$ for $z \in D$.

A classical paper of Alexander [1] shows that such functions are univalent in $D$. MacGregor [2, Theorem 1] considered the class $R$ and developed the usual distortion and coefficient results, all of which are immediate consequences of the representation theorem for functions of positive real part [3].

An omission from MacGregor's paper is a consideration of a distortion theorem for $\left|z f^{\prime}(z) / f(z)\right|$. Indeed, it appears that no such result has been proved. The object of this note is to give such an estimate.

2. Results and proofs. We begin by stating MacGregor's results (loc. cit).

THEOREM A.

$$
\text { Let } f \in R \text { and } f(z)=z+\sum_{n=2}^{\infty} a_{n} z^{n}, \quad \text { for } z \in D \text {. }
$$

Then for $z=r e^{i \theta}, 0 \leqslant r<1$

$$
\begin{gathered}
\left|a_{n}\right| \leqslant 2 / n, \quad n=2,3, \ldots, \\
\left|f^{\prime}(z)\right| \leqslant(1+r) /(1-r), \\
\operatorname{Re} f^{\prime}(z) \geqslant(1-r) /(1+r), \\
-r+2 \log (1+r) \leqslant|f(z)| \leqslant-r-2 \log (1-r) .
\end{gathered}
$$

We now add the following

THEOREM 1. Let $f \in R$. Then for $z=r e^{i \theta}, 0<r<1$,

$$
\left|\frac{z f^{\prime}(z)}{f(z)}\right|<\frac{K}{(1-r) \log (1-r)^{-1}},
$$

where $K$ is an absolute constant. This growth rate is best possible.

Received by the editors December 26, 1984 and, in revised form, September 9, 1985.

1980 Mathematics Subject Classification (1985 Revision). Primary 30C45.

(C1986 American Mathematical Society $0002-9939 / 86 \$ 1.00+\$ .25$ per page 
Proof. Since $\operatorname{Re} f^{\prime}(z)>0$ for $z \in D$, we can write [3]

$$
f^{\prime}(z)=\frac{1}{2 \pi} \int_{0}^{2 \pi} \frac{1+z e^{-i t}}{1-z e^{-i t}} d \mu(t),
$$

where $\mu$ is increasing and $\mu(2 \pi)-\mu(0)=2 \pi$. Thus,

$$
\left|f^{\prime}(z)\right| \leqslant \frac{1}{2 \pi} \int_{0}^{2 \pi}\left|\frac{1+z e^{-i t}}{1-z e^{-i t}}\right| d \mu(t) .
$$

We now use a method of Twomey [6] to estimate the above integrand by noting that, for $r<1$,

$$
\left|\frac{1+z e^{-i t}}{1-z e^{-i t}}\right| \leqslant \frac{2 r \log \left((1+r) /\left|1-z e^{-i t}\right|\right)}{(1-r) \log ((1+r) /(1-r))}+1
$$

Hence

$$
\begin{aligned}
\left|f^{\prime}(z)\right| \leqslant & \frac{2 r \log (1+r)}{(1-r) \log ((1+r) /(1-r))} \\
& +\frac{1}{\pi} \int_{0}^{2 \pi} \frac{r \log \left|1-z e^{-i t}\right|^{-1}}{(1-r) \log ((1+r) /(1-r))} d \mu(t)+1 .
\end{aligned}
$$

Next we note that, from (2),

$$
\frac{f^{\prime}(z)-1}{z}=\frac{1}{\pi} \int_{0}^{2 \pi} \frac{e^{-i t}}{1-z e^{-i t}} d \mu(t),
$$

and so

$$
F(z)=\frac{1}{\pi} \int_{0}^{2 \pi} \log \frac{1}{1-z e^{-i t}} d \mu(t)
$$

where

$$
F(z)=\int_{0}^{z} \frac{f^{\prime}(\zeta)-1}{\zeta} d \zeta
$$

Thus,

$$
\operatorname{Re} F(z)=\frac{1}{\pi} \int_{0}^{2 \pi} \log \frac{1}{\left|1-z e^{-i t}\right|} d \mu(t)
$$

From (3) and (5) we obtain

(6)

$$
\left|f^{\prime}(z)\right| \leqslant \frac{2 r \log (1+r)}{(1-r) \log ((1+r) /(1-r))}+\frac{|z F(z)|}{(1-r) \log ((1+r) /(1-r))}+1 \text {. }
$$

Now (1) and (4) gives

$$
z F(z)=f(z)-z+\sum_{n=2}^{\infty} \frac{a_{n}}{n-1} z^{n}
$$

and so using the coefficient estimate in Theorem $\mathrm{A}$ we have

$$
|z F(z)| \leqslant|f(z)|+3 r+(2 / r)(1-r) \log (1-r)^{-1} .
$$


Finally, from (6), (7) and the lower bound for $|f(z)|$ in Theorem A we obtain Theorem 1.

The function $f(z)=-z+2 \log (1-z)^{-1}$ shows that the growth rate in Theorem 1 is best possible.

We remark that a sharp estimate in Theorem 1 remains an open question.

An immediate consequence of Theorem 1 is that if $f \in R$ and is bounded, then

$$
M\left(r, f^{\prime}\right)=O(1)\left[(1-r) \log (1-r)^{-1}\right]^{-1} .
$$

Following Twomey [5], we have, in the opposite direction,

THEOREM 2. There exists a bounded $f \in R$ such that

$$
\limsup _{r \rightarrow 1} M\left(r, f^{\prime}\right)(1-r) \log \frac{1}{1-r}>0 .
$$

Proof. The examples given in $[5, \S 9]$ will suffice on writing

$$
f^{\prime}(z)=\sum_{n=1}^{\infty} \lambda_{n} \frac{1+r_{n} e^{-i \theta_{n} z}}{1-r_{n} e^{-i \theta_{n} z}}
$$

for $z \in D$, with $\left\{r_{n}\right\},\left\{\theta_{n}\right\}$ and $\left\{\lambda_{n}\right\}$ defined as in $[5, \S 9]$. It is then clear that (8) holds and that $f$ is bounded.

REMARK. Theorem 1 can also be proved using the less elementary method of Ruschweyh [4], but this also appears not to give the sharp result.

\section{REFERENCES}

1. J. W. Alexander, Functions which map the interior of the unit circle upon simple regions, Ann. of Math. (2) 17 (1915), 12-22.

2. T. H. MacGregor, Functions whose derivative has a positive real part, Trans. Amer. Math. Soc. 104 (1962), 532-537.

3. P. L. Duren, Univalent functions, Springer-Verlag, 1983.

4. S. Ruscheweyh, Nichtlineare Extremalprobleme für holomorphe Stieltjesintegrale, Math. Z. 142 (1975), 19-23.

5. J. B. Twomey, On the derivative of a starlike function, J. London Math. Soc. (2) 2 (1970), 99-110.

6. On starlike functions, Proc. Amer. Math. Soc. 24 (1970), 95-97.

Department of Mathematics and Computer Science, University College of Swansea, Swansea SA2 8PP, WALES 